\title{
Factors Affecting Japanese Pond Smelt (Hypomesus nipponensis) Stock Trajectory in Lake Kasumigaura and Kitaura
}

\author{
Ashneel Ajay Singh1, Noriyuki Sunoh², Shintaro Niwa², Fumitaka Tokoro², \\ Daisuke Sakamoto', Naoki Suzuki', Kazumi Sakuramoto ${ }^{{ }^{*}}$ \\ ${ }^{1}$ Department of Ocean Science and Technology, Tokyo University of Marine Science and Technology, Tokyo, \\ Japan \\ ${ }^{2}$ Freshwater Branch Office, Ibaraki Fisheries Research Institute, Ibaraki, Japan \\ Email: *sakurak@kaiyodai.ac.jp
}

Received 5 February 2015; accepted 26 March 2015; published 30 March 2015

Copyright @ 2015 by authors and Scientific Research Publishing Inc.

This work is licensed under the Creative Commons Attribution International License (CC BY). http://creativecommons.org/licenses/by/4.0/

(c) (i) Open Access

\section{Abstract}

The Japanese pond smelt (Hypomesus nipponensis) stock has been observed to fluctuate quite rigorously over the years with sustained periods of low catch in Lake Kasumigaura and Kitaura of the Ibaraki prefecture, Japan which would adversely affect the socioeconomic livelihood of the local fishermen and fisheries industry. This study was aimed at determining the factors affecting the stock fluctuation of the pond smelt through the different years in the two lakes. Through exploratory analysis it was found that the pond smelt had significant relationship with total phosphorus (TP) level in both lakes. The global mean land and ocean temperature index (LOTI) was also found to be indirectly related to the pond smelt stock in lake Kasumigaura and Kitaura at the latitude band of $24^{\circ} \mathrm{N}$ to $90^{\circ} \mathrm{N}(I)$. Both TP and LOTI had inverse relationship with pond smelt trajectory in both lakes. For both Lake Kasumigaura and Kitaura, TP for the individual lakes and LOTI (I) were used as independent variables using generalized linear model and response surface methods for modeling the stock dynamics of the pond smelt in the two lakes. Model selection was based on significant parameter estimates $(p<0.05)$, Akaikes Information Criterion and $R^{2}$ values. Phosphorus loading is an indication of increasing anthropogenic activities in the surrounding area having negative impact on the pond smelt population. When management decisions are being made regarding pond smelt fishery and sustainability plans in the Ibaraki prefecture, the effects of TP and LOTI should be taken into account. Future research needs to be directed towards deeper understanding the mechanisms by which TP and LOTI affect pond smelt population in Lake Kasumigaura and Kitaura for more effective management.

\footnotetext{
"Corresponding author.
} 


\section{Keywords}

\section{Pond Smelt, Lake Kasumigaura, Lake Kitaura, Phosphorus, Surface Temperature}

\section{Introduction}

The Japanese pond smelt, Hypomesus nipponensis McAllister (revised by [1]) is a commercially important lake fish in Japan [2]-[6]. It is distributed substantially among the Lakes Ogawara, Abashiri, Suwa, Kasumigaura and Kitaura as well as coastal sea areas around Japan [2] [7] [8]. The pond smelt is of cultural importance as a symbol for freshwater fisheries in the area around Lake Kasumigaura and Kitaura [6]. Their population has been observed to fluctuate quite intensively over time in the two lakes and has reached comparatively low levels and sustained low over a number of years in recent history. Understanding of such patterns is important for effective management and for both economical and biological sustainability of the pond smelt.

Lake Kasumigaura, the second largest lake in Japan (after Lake Biwa) and the much smaller nearby Lake Kitaura (Figure 1) are freshwater shallow lakes with an average depth of four meters, located on the East side of the Kanto plain in Ibaraki prefecture, Japan [9] [10]. The landscape around the two lakes is dominated by forest, paddy fields, plowed fields and water, with the traditional industries of the area being livestock management, agriculture and fishery production [9]. Matsushita [9] studied the changes in land use from 1979 to 1996 around the Lake Kasumigaura and Kitaura Basin and reported significant increase in human land use such as agricultural activities, residential homes and recreational facilities.

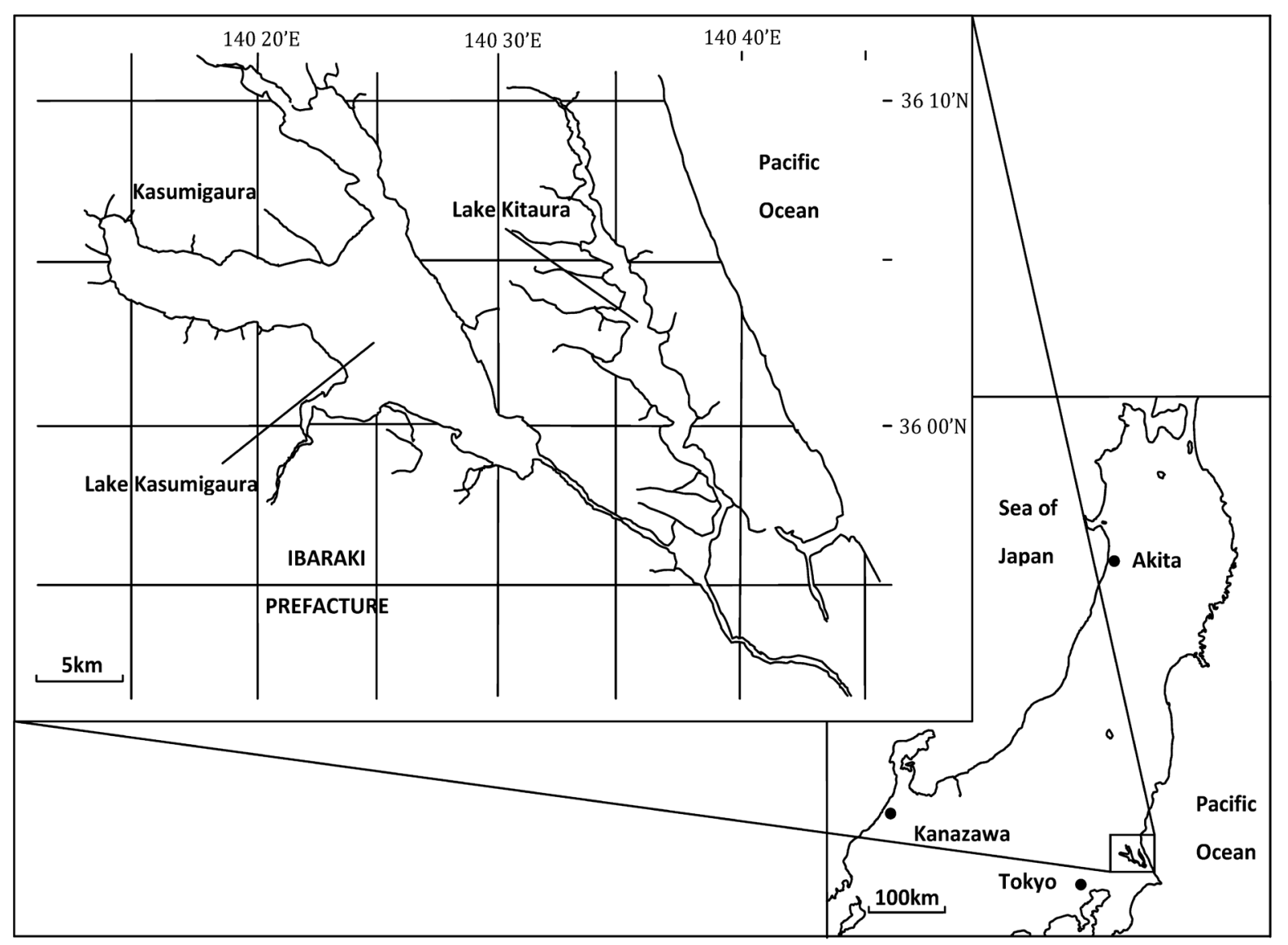

Figure 1. Map of Kasumigaura, Ibaraki Prefecture, Japan, showing the location of Lake Kasumigaura and Kitaura, the study site and stock distribution for the Japanese pond smelt (H. nipponensis). 
Pond smelts have been shown to be affected by biological and environmental factors previously [11]-[14]. In a study as in [11], in Lake Yunoko it was found that the population of pond smelt are almost absent in anoxic areas where the dissolved oxygen was below $3 \mathrm{mg} / \mathrm{l}$, showing that dissolved oxygen concentration of lake water has a strong influence on the population dynamics of the pond smelt (Hypomesus olidus). Hasenbein [14] showed that negative correlation exists between turbidity of water and feeding frequency of juvenile delta smelt (Hypomesus transpacificus) from the San Francisco Bay Delta, USA. Sharma [12] studied the impact of changes in climatic condition (air temperature) and invasion of rainbow smelt (Osmerus mordax) on cisco (Coregonus artedii) population for over 13,000 lakes in Winsconsin, USA. Results showed that the negative impact of changes in air temperature on cisco will be much larger than invasion of rainbow smelt by the year 2100 . Heithaus [15] and Atkinson [16] concluded that the vulnerability to predation is a significant factor in determining the survival and mortality of fish stocks in lakes and rivers. Toda and Wada [13] showed that the seasonal change in size of prawn (macrobrachium nipponense), goby (Tridentiger obscurus), pond smelt (Hypomesus transpacificus) and zooplankton show similar patterns in Lake Kasumigaura.

Bryan and Ludsin [17] studied the impact of different nutrient levels and introduction of a predatory species on the food web structure in three lakes in Ohio, USA. Results showed that changes in nutrient content including phosphorus had higher impact on lake food web structure compared with changes in predatory species. Human land use and developments have probably resulted in the increased loading of nutrients including phosphorus in Lake Kasumigaura and Kitaura [9]. Phosphorus loading has been shown to be the leading cause of eutrophication in lake ecosystems, which leads to anoxia, increase in turbidity and changes in the community structure of primary producers, eventually leading to changes in the dynamics of higher trophic level vertebrates [18]-[21].

In understanding population dynamics it is important to study the habitat of the fish as this plays a significant role in their survival both as juveniles and as they grow into adult forms [22]. Here, a habitat is the interaction of a fish species with biotic and abiotic factors to support a healthy population [23]. The mechanisms behind the trajectory pattern of fish are complex as various biotic and abiotic factors might be interacting and operating together resulting in annual changes in population. It is critical to understand the relationship of a fish to its habitat and long-term data are essential to compare trends of variables and identify their linkages to fish population dynamics [24] [25] in order to better manage a fishery.

The purpose of this study was to determine the intrinsic and environmental factors affecting the fluctuation patterns of the Japanese pond smelt (H. nipponensis) through the years for Lake Kasumigaura and Kitaura. The objectives were to: 1) carry out exploratory analysis and determine if relationships exist between pond smelt stocks and variables from data on nutrient levels in lake, physiochemical data for each lake and biological data on organisms; 2) determine if the climatic condition of surface temperature of the latitude band above the two lakes have any relation to pond smelt stock as the effect of air temperature above lakes on lake fish has been shown in [12]; 3) use variables exhibiting significant relationships to pond smelt stock trajectory to develop reasonable stock reproduction model for the Japanese pond smelt (H. nipponensis) in Lake Kasumigaura and Lake Kitaura respectively.

\section{Materials and Method}

\subsection{Data}

The catch data for the stock of the Japanese pond smelt $H$. nipponensis in Lake Kasumigaura and Kitaura for the range of years from 1972 to 2008 was obtained from the Ibaraki Prefectural Fisheries Experiment Station (IFES), Ibaraki, Japan and as calculated in [26] and [27]. Spawning occurs annually in the two lakes between mid-January to mid-March and pond smelts recruit to the fishery when they are four to six months old. They have a life span of one year and the fishermen harvest pond smelt in the two lakes annually from July to December using trawl net [5] [28]-[31] and provide the catch data to IFES. IFES also carries out trawl surveys just before the initiation of the fishing season. Catch size of pond smelt ranges from $\sim 6 \mathrm{~cm}$ in July to $\sim 10 \mathrm{~cm}$ from August to December [28] and they are distributed throughout Lake Kasumigaura and Kitaura encompassing an area of approximately $220 \mathrm{~km}^{2}$ (Figure 1).

Figures 2(a)-(b) show the trajectory of the Japanese pond smelt (H. nipponensis) from the year 1972 to 2008 for Lake Kasumigaura and Kitaura respectively. For Lake Kasumigaura (Figure 2(a)), there was a decreasing trend of catch for the years 1974-1976, 1986-1988, 1993-1995 and 1997-2000, while the years 1980-1984, 1988-1991 and 1995-1997 followed an increasing trend. For the other years, the trend fluctuated annually. The 


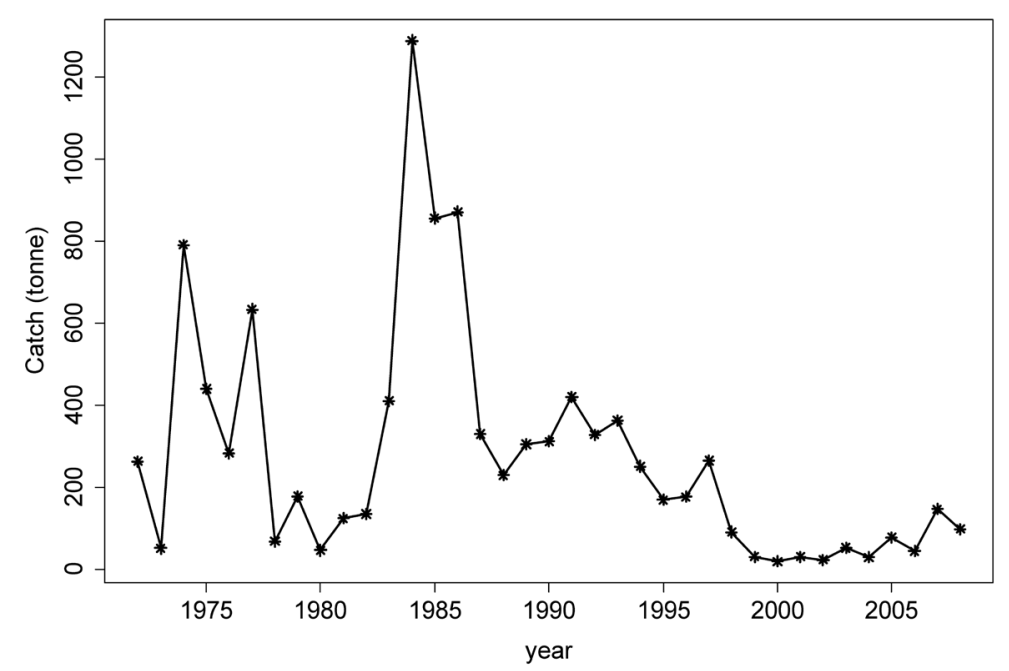

(a)

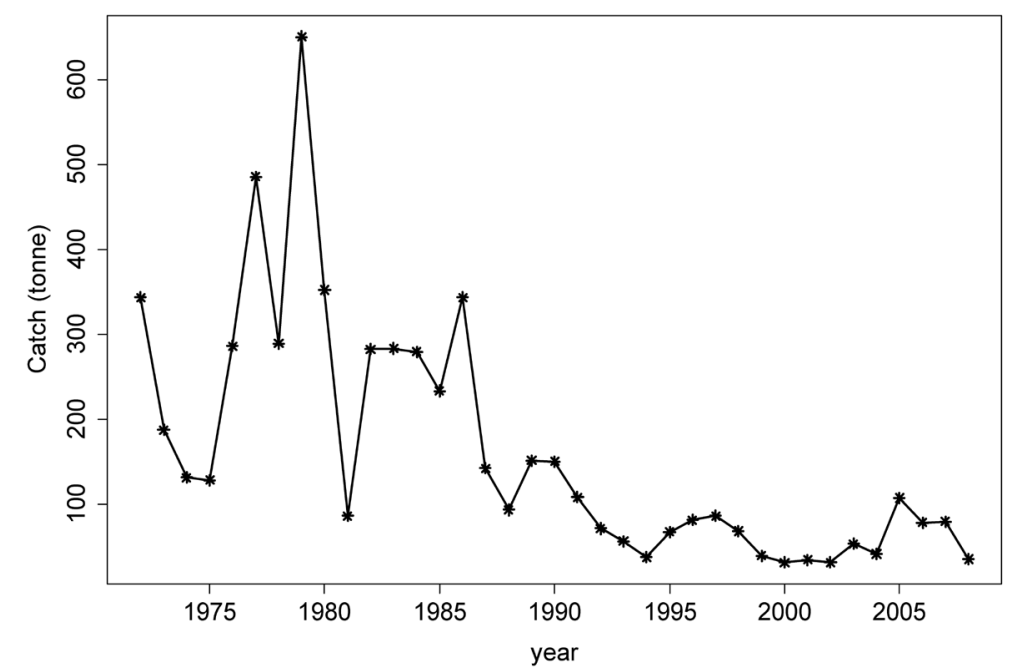

(b)

Figure 2. (a) The catch dynamics of the Japanese pond smelt (H. nipponensis) in Lake Kasumigaura from 1972 to 2008. (b) The catch dynamics of the Japanese pond smelt (H. nipponensis) in Lake Kitaura from 1972 to 2008.

catch peaked in 1984 followed by a sharp decline, while other significant peaks for catch of pond smelt can be observed for the years 1974, 1977 and 1986. In the year 2000 the catch volume was at its lowest point and seemed to recover to some extent by the year 2007. For Lake Kitaura (Figure 2(b)), a decreasing trend can be observed for the years 1972-1975, 1979-1981, 1986-1988, 1989-1994 and 1997-2000, while an increasing trend was seen for the years 1975-1977, 1981-1982, and 1994-1997. For the other years, the trend had an annual fluctuation of higher and lower catch. The peak catch of pond smelt for Lake Kitaura can be seen in the year 1979 which was followed by a sharp decline. Other significant peaks can be observed for the years 1972, 1977 and 1986. The lowest catch volume was observed for the year 2000, following which the stock recovered to some extent by the year 2007 before declining again by the year 2008 .

From Figures 2(a)-(b) a similar pattern can be observed. Before 1988, the catch trend for both lakes showed two peaks that are quite similar. Around 1977 and 1986, the catches in Lake Kasumigaura were significantly high. Similarly, around 1977 and 1986, the catches in Lake Kitaura were also significantly high. From 1986 to 1989 the catch trajectory pattern for both lakes were almost identical and after 1990, catches in both lakes generally showed a decreasing pattern which continued up to the year 2004. 
The catch per unit effort (CPUE) is a suitable representative of the pond smelt stock for Lake Kasumigaura and Kitaura but the effort data from IFES was only available from 1998 to 2008. This limited the CPUE calculation for a period of only 11 years which would be insufficient to effectively compare trends and linkages between variables. On the other hand, the catch data was available for a period of 37 years for both Lake Kasumigaura and Kitaura, hence it would be better suited for trend analysis and comparisons with variables. To justify the suitability of catch data as representative of pond smelt stock trajectory for the two lakes, it was compared with the CPUE data.

Other variable data obtained for Lake Kasumigaura and Kitaura from IFES included: 1) data on the nutrient levels such as chemical oxygen demand, dissolved oxygen, total nitrogen and total phosphorus (mg/l); 2) in situ data including water temperature $\left({ }^{\circ} \mathrm{C}\right)$, turbidity $(\mathrm{cm})$, chlorophyll $(\mu \mathrm{g} / \mathrm{l})$ and $\mathrm{pH}$; 3) biological catch data (tonnes) included grasscarp (Ctenopharyngodon idellus), crusian carp (Carassius auratus) eel (Anguilla japonica), borakind mullet (Mugil cephalus), prawn (Macrobachium nipponense), catfish (Sarcocheilichyhys variegates microoculus), clam (Corbicula japonica) and icefish (Salangichthys microdon) as the fish and shellfish species. Climatic data for global mean land and ocean temperature index (LOTI) for the latitude band of $24^{\circ} \mathrm{N}$ to $90^{\circ} \mathrm{N}$ was obtained from the National Aeronautics and Space Administration (NASA), Goddard Institute for Space studies, Goddard Space Flight Center, Science and Exploration Directorate, Earth Science Division (http://data.giss.nasa.gov/gistemp).

\subsection{Regression Analysis and Unit Root Test}

Regression analysis was carried out to screen all the variables and determine which individual independent variables correlated to the dependent variables of pond smelt catch and CPUE time series in Lake Kasumigaura and Kitaura. In order to determine if catch data could be used as a representative of pond smelt stock in Lake Kasumigaura and Kitaura it was compared with the available CPUE data from 1998 to 2008. The CPUE data from 1998 to 2008 for Lake Kasumigaura and Kitaura $\left(P_{x}\right.$ and $\left.P_{y}\right)$ was subjected to regression analysis against nutrient, in situ, biological and climatic data. The same treatment was applied to catch data from 1998 to 2008 for the two lakes $\left(C_{x}\right.$ and $\left.C_{y}\right)$ for comparison. The determination coefficient was also calculated between the CPUE and catch for pond smelt in both lakes from 1998 to 2008 to examine how well they align with each other.

Regression analysis was applied to the pond smelt catch data from 1972 to 2008 for Lake Kasumigaura and Kitaura $\left(C_{u}\right.$ and $\left.C_{v}\right)$ against the various nutrient, in situ, biological and climatic data. Variables which belonged exclusively to a particular lake, such as catch data for a fish species in a particular lake, were used in regression analysis just for that particular lake as this made sense ecologically. These results were also compared with the regression results of CPUE from 1998 to 2008.

Time series data which have a deterministic trend have a stationary process where changes in time series trend or shocks have transitory effects. When shocks have permanent effect the time series have a stochastic trend or unit root. The presence of a unit root in a time series can result in spurious correlations in statistical techniques such as regression analysis [32]-[34]. Pond smelt catch and CPUE data for Lake Kasumigaura and Kitaura as well as variables which exhibited significance correlation with pond smelt data in each lake were subjected to MacKinnons and Augmented Dickey-Fuller unit root tests to confirm whether any of the time series data had a non-stationary process [32]-[34].

\subsection{Stock Reproduction Model}

Independent variables which individually showed significant relationships to the catch and CPUE in regression analysis were fitted together to reconstruct the time series stock trajectory or stock reproduction model for the pond smelt in Lake Kasumigaura and Kitaura. One or more variables were to be selected from each group which included: 1) data on the nutrient levels; 2) in situ data; 3) biological data and 4) climatic data for each lake. Variables which exhibited sufficient correlation with pond smelt catch data for each lake and had lowest AIC values in each group were to be used as independent variables for the stock reproduction model for the individual lakes. Variables with $p<0.05$ were recognized as significant relationship of the independent variable with the dependent variable $\left(C_{u}\right.$ and $\left.C_{v}\right)$. In cases where $p \geq 0.05$ but $p<0.1$ the variables were treated as weakly significant and also considered for modeling. Variables were rejected for $p \geq 0.1$ and in cases where all variable for an entire group had $p \geq 0.1$, no variables were selected from the group. The parent formula used for the stock reproduction model for Lake Kasumigaura was a Generalized Linear Model (GLM) shown below 


$$
\ln \left(C_{u, t}\right)=\ln \left(\alpha_{0}\right)+\alpha_{1} m_{1, t-n}+\alpha_{2} m_{2, t-n}+\cdots+\alpha_{k} m_{k, t-n}+\varepsilon
$$

where $C_{u}$ is the catch data for pond smelt in Lake Kasumigaura, $\alpha_{0}$ is the intercept parameter, $\alpha_{1}, \alpha_{2} \ldots \alpha_{k}$ are parameter estimates, $m_{1}, m_{2} \ldots m_{\mathrm{k}}$ are the independent variables selected based on the results of the regression analysis for Lake Kasumigaura, $t$ is the year with $n=0,1$ and $\varepsilon$ is a normally distributed random variable. The response surface methodology (RSM) which has been previously described [35]-[38] is a set of statistical and mathematical techniques which uses linear and polynomial functions to fit variables in order to describe data or system being studied. RSM was used to modify the Equation (1) to incorporate second and third order polynomials to investigate if the variables fit better with this method (Equation (2))

$$
\ln \left(C_{u, t}\right)=\ln \left(\alpha_{0}\right)+\alpha_{1} m_{1, t-n}+\alpha_{2} m_{2, t-n}+\alpha_{3} m_{1, t-n}^{2}+\alpha_{4} m_{2, t-n}^{2}+\cdots+\alpha_{k} m_{k, t-n}^{s}+\varepsilon
$$

where $s=1,2$, 3. We also used the GLM (Equation (3)) and RSM (Equation (4)) as the parent formulas for stock reproduction model for Lake Kitaura as shown below

$$
\begin{gathered}
\ln \left(C_{v, t}\right)=\ln \left(\alpha_{0}^{\prime}\right)+\alpha_{1}^{\prime} q_{1, t-n}+\alpha_{2}^{\prime} q_{2, t-n}+\cdots+\alpha_{k}^{\prime} q_{k, t-n}+\varepsilon^{\prime} \\
\ln \left(C_{v, t}\right)=\ln \left(\alpha_{0}^{\prime}\right)+\alpha_{1}^{\prime} q_{1, t-n}+\alpha_{2}^{\prime} q_{2, t-n}+\alpha_{3}^{\prime} q_{1, t-n}^{2}+\alpha_{4}^{\prime} q_{2, t-n}^{2}+\cdots+\alpha_{k}^{\prime} q_{k, t-n}^{s}+\varepsilon^{\prime}
\end{gathered}
$$

where $C_{v}$ is the catch data for pond smelt in Lake Kitaura, $\alpha_{0}^{\prime}$ is the intercept parameter, $\alpha_{1}^{\prime}, \alpha_{2}^{\prime}, \cdots, \alpha_{k}^{\prime}$ are parameter estimates, $q_{1}, q_{2}, \cdots, q_{k}$ are the independent variables selected based on the results of the regression analysis for Lake Kitaura and $\varepsilon^{\prime}$ is a normally distributed random variable.

Various possible combinations of variables for Equations (1)-(4) were used by elimination to reach the optimum model for the catch dynamics of the pond smelt for each lake. The CPUE for pond smelt in Lake Kasumigaura from 1998 to $2008\left(P_{x}\right)$ and Lake Kitaura from 1998 to $2008\left(P_{y}\right)$ was also modeled by substituting $C_{u}$ and $C_{v}$ in Equations (1)-(4) with $P_{x}$ and $P_{y}$. Each combination of variables was checked for significant parameter estimates at $p<0.05$. The actual CPUE and catch dynamics and the predicted dynamics from the selected models were plotted for both Lake Kasumigaura and Kitaura. The Akaike Information Criterion (AIC) and $R^{2}$ value were used to evaluate each model and form a basis for model selection at $p<0.05$ [39].

All statistical analysis for this study was carried out using the statistical software "R", version 3.0.1 [40].

\section{Results}

\subsection{Catch and CPUE Comparison}

The abbreviated forms of variables that are of interest and the independent variables which showed correlations with dependent variables are shown in Table 1 with their descriptions. The regression results of the pond smelt CPUE from 1998 to 2008 for Lake Kasumigaura and Kitaura $\left(P_{x}\right.$ and $\left.P_{y}\right)$ against independent variables are shown in Table 2. For Lake Kasumigaura the CPUE showed significant correlation with the LOTI latitude band $24^{\circ} \mathrm{N}$ to $90^{\circ} \mathrm{N}\left(l_{t}\right)$ and weak correlation with total phosphorus $\left(w_{t}\right)$. For Lake Kitaura significant correlation of the CPUE was observed for LOTI latitude band $l_{t}$ and grasscarp (C. idellus) $\left(b_{t}\right)$ with weak correlation against total phosphorus $\left(z_{t}\right)$. In all cases the independent variables had higher correlation in year $t$ and weaker relationship with lag of one year at $t-1$. When we compare these results with the regression of pond smelt catch from 1998 to 2008 for each lake against independent variables shown in Table 3, the results are almost identical.

Figure 3 shows the correlation between the pond smelt catch and CPUE for Lake Kasumigaura and Kitaura respectively for the years 1998 to 2008. The determination coefficients are 0.927 and 0.952 with $p<0.05$. CPUE and catch showed very high correlation and both showed correlation to the same variables (Table 2 and Table 3), therefore we assumed that catch could possibly be a suitable representative for pond smelt stock trajectory for the two lakes. Due to the limitation of available effort data, the range of data for CPUE was only available for a short period from 1998 to 2008 whereas the catch data available from 1972 to 2008 was quite extensive which made it more suitable for comparing trends and identifying linkages against various variables over long time series compared to short time series for CPUE data.

\subsection{Regression Analysis and Unit Root Test}

The results for regression analysis are shown in Table 4 for individual variables against the Japanese pond smelt 
Table 1. Table showing variables of interest for this study relating to Lake Kasumigaura and Kitaura.

\begin{tabular}{|c|c|c|}
\hline Туре & Variable & Description \\
\hline \multirow{6}{*}{ Dependent } & $C_{u}$ & Japanese pond smelt (H. nipponensis) catch 1972-2008 Lake Kasumigaura \\
\hline & $C_{v}$ & Japanese pond smelt (H. nipponensis) catch 1972-2008 Lake Kitaura \\
\hline & $C_{x}$ & Japanese pond smelt (H. nipponensis) catch 1998-2008 Lake Kasumigaura \\
\hline & $C_{y}$ & Japanese pond smelt (H. nipponensis) catch 1998-2008 Lake Kitaura \\
\hline & $P_{x}$ & Japanese pond smelt (H. nipponensis) CPUE 1998-2008 Lake Kasumigaura \\
\hline & $P_{y}$ & Japanese pond smelt (H. nipponensis) CPUE 1998-2008 Lake Kitaura \\
\hline \multirow{4}{*}{ Independent } & $w$ & Total phosphorus Lake Kasumigaura \\
\hline & z & Total phosphorus Lake Kitaura \\
\hline & $b$ & Grasscarp (C. idellus) Lake Kitaura \\
\hline & $l$ & Global mean land and ocean temperature index (LOTI) for the latitude band $24^{\circ} \mathrm{N}$ to $90^{\circ} \mathrm{N}$ \\
\hline
\end{tabular}

Table 2. Regression results for the Japanese pond smelt (H. nipponensis) CPUE in Lake Kasumigaura and Kitaura against independent variables for the years 1998 to 2008. Variables with $p<0.05$ are highly significant and those with $0.05 \leq p<$ 0.10 are weakely significant.

\begin{tabular}{|c|c|c|c|c|c|c|c|c|c|}
\hline \multicolumn{5}{|c|}{ Lake Kasumigaura (year $t$ ) } & \multicolumn{5}{|c|}{ Lake Kasumigaura (year $t-1$ ) } \\
\hline Variables & $R$ & $R^{2}$ & $p$-value & $\begin{array}{c}\text { AIC } \\
\text { value }\end{array}$ & Variables & $R$ & $R^{2}$ & $p$-value & $\begin{array}{c}\text { AIC } \\
\text { value }\end{array}$ \\
\hline$P_{x, t}, l_{t}$ & -0.886 & 0.785 & $2.82 \times 10^{-4}$ & 72 & $P_{x, t}, l_{t-1}$ & -0.381 & 0.145 & $2.77 \times 10^{-2}$ & 81 \\
\hline$P_{x, t}, w_{t}$ & -0.329 & 0.108 & $3.24 \times 10^{-2}$ & 79 & $P_{x, t}, w_{t-1}$ & -0.138 & 0.019 & $7.05 \times 10^{-2}$ & 89 \\
\hline \multicolumn{5}{|c|}{ Lake Kitaura (year $t$ ) } & \multicolumn{5}{|c|}{ Lake Kitaura (year $t-1$ ) } \\
\hline$P_{y, t}, l_{t}$ & -0.772 & 0.596 & $5.40 \times 10^{-3}$ & 81 & $P_{y, t}, l_{t-1}$ & -0.412 & 0.170 & $2.37 \times 10^{-2}$ & 82 \\
\hline$P_{y, t}, Z_{t}$ & -0.225 & 0.051 & $5.07 \times 10^{-2}$ & 80 & $P_{y, t}, Z_{t-1}$ & -0.113 & 0.012 & $7.56 \times 10^{-2}$ & 84 \\
\hline$P_{y, t}, b_{t}^{*}$ & 0.786 & 0.618 & $1.20 \times 10^{-2}$ & 66 & $P_{y, t}, b_{t-1}^{*}$ & 0.132 & 0.018 & $7.55 \times 10^{-2}$ & 67 \\
\hline
\end{tabular}

*Data only available from 1998 to 2006.

Table 3. Regression results for the Japanese pond smelt ( $H$. nipponensis) catch in Lake Kasumigaura and Kitaura against independent variables for the years 1998 to 2008. Variables with $p<0.05$ are highly significant and those with $0.05 \leq p<$ 0.10 are weakely significant.

\begin{tabular}{|c|c|c|c|c|c|c|c|c|c|}
\hline \multirow[b]{2}{*}{ Variables } & \multicolumn{5}{|c|}{ Lake Kasumigaura (year $t$ ) } & \multicolumn{3}{|c|}{ Lake Kasumigaura (year $t-1$ ) } & \multirow[b]{2}{*}{$\begin{array}{c}\text { AIC } \\
\text { value }\end{array}$} \\
\hline & $R$ & $R^{2}$ & $p$-value & $\begin{array}{c}\text { AIC } \\
\text { value }\end{array}$ & Variables & $R$ & $R^{2}$ & $p$-value & \\
\hline$C_{x, t}, l_{t}$ & -0.752 & 0.565 & $7.64 \times 10^{-3}$ & 108 & $C_{x, t}, l_{t-1}$ & -0.571 & 0.326 & $8.48 \times 10^{-2}$ & 104 \\
\hline$C_{x, t}, w_{t}$ & -0.338 & 0.114 & $3.10 \times 10^{-2}$ & 116 & $C_{x, t}, w_{t-1}$ & -0.257 & 0.065 & $4.74 \times 10^{-2}$ & 107 \\
\hline \multicolumn{5}{|c|}{ Lake Kitaura (year $t$ ) } & \multicolumn{5}{|c|}{ Lake Kitaura (year $t-1$ ) } \\
\hline$C_{y, t}, l_{t}$ & -0.766 & 0.587 & $5.98 \times 10^{-3}$ & 98 & $C_{y, t}, l_{t-1}$ & -0.387 & 0.150 & $2.69 \times 10^{-2}$ & 97 \\
\hline$C_{y, t}, z_{t}$ & -0.205 & 0.042 & $5.85 \times 10^{-2}$ & 107 & $C_{y, t}, Z_{t-1}$ & -0.139 & 0.019 & $6.69 \times 10^{-2}$ & 98 \\
\hline$C_{y, t}, b_{t}^{*}$ & 0.729 & 0.531 & $2.59 \times 10^{-2}$ & 82 & $C_{y, t}, b_{t-1}^{*}$ & 0.292 & 0.085 & $4.83 \times 10^{-2}$ & 80 \\
\hline
\end{tabular}

*Data only available from 1998 to 2006.

(Hypomesus nipponensis) catch for Lake Kasumigaura and Kitaura for the years 1972 to 2008 . Table 1 can be referred to for the definitions of the variables. In Table 4, we only show the results for variables with $p<0.05$. From group 1) data on nutrient levels, TP in Lake Kasumigaura $\left(w_{t-1}\right)$ and Lake Kitaura $\left(z_{t-1}\right)$ showed most significant relationships with pond smelt $\left(H\right.$. nipponensis) catch in Lake Kasumigaura $\left(C_{u, t}\right)$ and Lake Kitaura $\left(C_{v, t}\right)$ 
Table 4. Regression results for individual variables against the Japanese pond smelt (H. nipponensis) catch in Lake Kasumigaura and Kitaura for the years 1972 to 2008 (year $t$ ) and 1973 to 2008 (year $t-1$ ). Variables with $p<0.05$ are highly significant.

\begin{tabular}{|c|c|c|c|c|c|c|c|c|c|}
\hline \multicolumn{5}{|c|}{ Lake Kasumigaura (year $t$ ) } & \multicolumn{5}{|c|}{ Lake Kasumigaura (year $t-1$ ) } \\
\hline Variables & $R$ & $R^{2}$ & $p$-value & $\begin{array}{c}\text { AIC } \\
\text { value }\end{array}$ & Variables & $R$ & $R^{2}$ & $p$-value & $\begin{array}{l}\text { AIC } \\
\text { value }\end{array}$ \\
\hline$C_{u, t}, l_{t}$ & -0.548 & 0.301 & $5.50 \times 10^{-4}$ & 503 & $C_{u, t}, l_{t-1}$ & -0.516 & 0.267 & $1.10 \times 10^{-3}$ & 517 \\
\hline$C_{u, t}, w_{t}$ & -0.579 & 0.336 & $1.72 \times 10^{-4}$ & 514 & $C_{u, t}, w_{t-1}$ & -0.585 & 0.342 & $1.78 \times 10^{-4}$ & 500 \\
\hline \multicolumn{5}{|c|}{ Lake Kitaura (year $t$ ) } & \multicolumn{5}{|c|}{ Lake Kitaura (year $t-1$ ) } \\
\hline$C_{v, t}, l_{t}$ & -0.657 & 0.431 & $1.01 \times 10^{-5}$ & 456 & $C_{v, t}, l_{t-1}$ & -0.606 & 0.368 & $8.89 \times 10^{-5}$ & 447 \\
\hline$C_{v, t}, z_{t}$ & -0.503 & 0.253 & $1.52 \times 10^{-3}$ & 466 & $C_{v, t}, Z_{t-1}$ & -0.582 & 0.338 & $2.00 \times 10^{-4}$ & 449 \\
\hline$C_{v, t}, b_{t}^{*}$ & 0.707 & 0.499 & $2.10 \times 10^{-6}$ & 428 & $C_{v, t}, b_{t-1}^{* *}$ & 0.661 & 0.437 & $2.09 \times 10^{-5}$ & 419 \\
\hline
\end{tabular}

*Data only available from 1972 to 2006; ${ }^{* *}$ Data only available from 1973 to 2006.

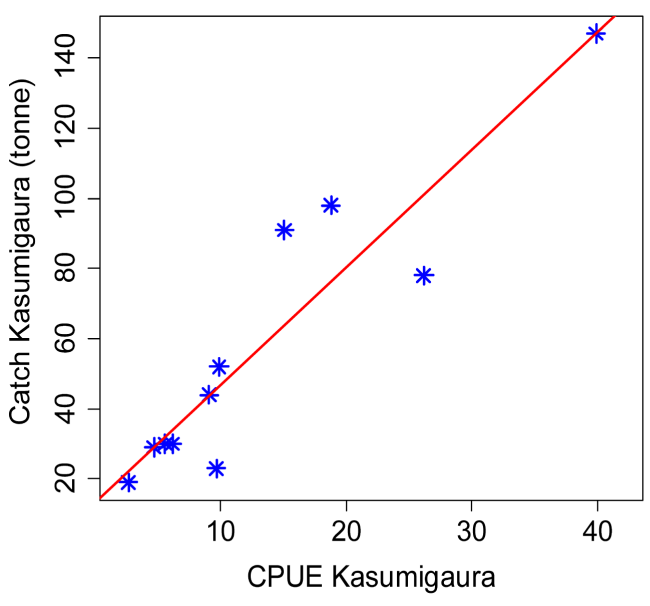

(a)

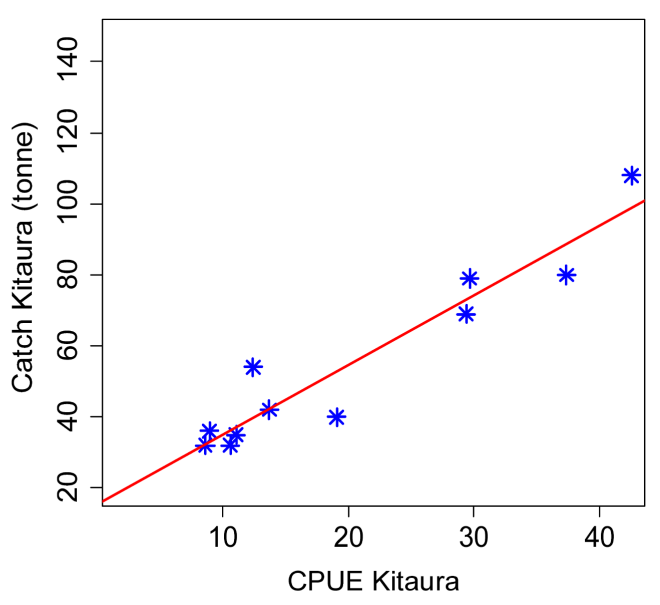

(b)

Figure 3. The relationship between the Japanese pond smelt (H. nipponensis) catch and CPUE for Lake Kasumigaura (a) and Kitaura (b) from 1998 to 2008. The determination coefficients are 0.927 and 0.952 respectively.

respectively. From group 2) in situ data, no significant relationship was observed with pond smelt dynamics in either lake. From group 2) biological data on the different fish and shellfish species, no significant relationships were detected for Lake Kasumigaura with only grasscarp (C. idellus) $\left(b_{t}\right)$ exhibiting significant relationship with pond smelt catch in Lake Kitaura (Table 4). From group 3) climatic data, LOTI for the latitude band $24^{\circ} \mathrm{N}$ to $90^{\circ} \mathrm{N}\left(l_{t}\right)$ showed significant relationship with pond smelt for both Lake Kasumigaura and Kitaura. The relationship of pond smelt for both lakes with this latitude band made ecological sense as Japan (including the two lakes) falls within this latitude band.

For Lake Kitaura we carried out further analysis to confirm if grasscarp really affects pond smelt trajectory or whether its dynamics is affected by the same variables as pond smelt. The results are presented in Table 5 where it can be seen that grasscarp is affected by the same variables as pond smelt in Lake Kitaura for the years 1972 to 2008 (Table 4) and 1998 to 2008 (Table 2 and Table 3). Grasscarp cannot be used as independent variable for pond smelt in Lake Kitaura as both pond smelt and grasscarp are affected by the same factors.

In regression analysis sometimes spurious correlation can arise. Unit root tests are statistical methods to identify such cases [32]-[34]. Table 6 shows the unit root test results for the independent and dependent variables used to determine relationships for this study. The value for the t-test (t-value) in all cases was $<0$ for MacKinnon's test (M-test) and Augmented Dickey-Fuller test (ADF-test) and significant at $p<0.05$ level which showed that all the variables tested had stationary processes and the relationships shown in Tables 2-5 are reliable and non-spurious. 
Table 5. Relationship of grasscarp catch for Lake Kitaura with independent variables.

\begin{tabular}{cccccc}
\hline Dependent variable & Independent variable & $R$ & $R^{2}$ & $p$-value & AIC value \\
\hline \multirow{2}{*}{$b_{t}(1972-2006)$} & $l_{t}$ & -0.458 & 0.210 & $5.60 \times 10^{-3}$ & 380 \\
& $z_{t}$ & -0.466 & 0.217 & $4.78 \times 10^{-3}$ & 379 \\
$b_{t}(1998-2006)$ & $l_{t}$ & -0.606 & 0.368 & $8.35 \times 10^{-2}$ & 79 \\
& $z_{t}$ & -0.078 & 0.006 & $9.41 \times 10^{-2}$ & 83 \\
\hline
\end{tabular}

Table 6. Results of unit root tests for variables used in regression analysis from Tables 2-5.

\begin{tabular}{|c|c|c|c|c|}
\hline \multirow{2}{*}{ Series } & \multicolumn{2}{|c|}{ M-test } & \multicolumn{2}{|c|}{ ADF-test } \\
\hline & t-value & $p$-value & $\mathrm{t}$-value & $p$-value \\
\hline$C_{u}$ 1972-2008 & -9.341 & $1.17 \times 10^{-10}$ & -9.341 & $<1.00 \times 10^{-2}$ \\
\hline$C_{v} 1972-2008$ & -6.776 & $1.38 \times 10^{-07}$ & -6.776 & $<1.00 \times 10^{-2}$ \\
\hline$C_{x} 1998-2008$ & -5.740 & $7.05 \times 10^{-4}$ & -5.740 & $<1.00 \times 10^{-2}$ \\
\hline$C_{y} 1998-2008$ & -3.523 & $9.68 \times 10^{-3}$ & -3.523 & $1.81 \times 10^{-2}$ \\
\hline$P_{x} 1998-2008$ & -5.474 & $9.32 \times 10^{-4}$ & -5.474 & $<1.00 \times 10^{-2}$ \\
\hline$P_{y} 1998-2008$ & -2.497 & $4.12 \times 10^{-2}$ & -2.497 & $1.47 \times 10^{-2}$ \\
\hline w 1972-2008 & -7.073 & $5.06 \times 10^{-8}$ & -7.073 & $<1.00 \times 10^{-2}$ \\
\hline z 1972-2008 & -6.879 & $1.04 \times 10^{-07}$ & -6.879 & $<1.00 \times 10^{-2}$ \\
\hline w 1998-2008 & -5.946 & $5.73 \times 10^{-4}$ & -5.946 & $<1.00 \times 10^{-2}$ \\
\hline z 1998-2008 & -8.747 & $5.14 \times 10^{-5}$ & -8.747 & $<1.00 \times 10^{-2}$ \\
\hline l 1972-2008 & -9.874 & $3.09 \times 10^{-11}$ & -9.874 & $<1.00 \times 10^{-2}$ \\
\hline l 1998-2008 & -4.383 & $3.22 \times 10^{-3}$ & -4.383 & $<1.00 \times 10^{-2}$ \\
\hline b 1972-2006 & -6.948 & $8.55 \times 10^{-8}$ & -6.948 & $<1.00 \times 10^{-2}$ \\
\hline b 1998-2006 & -3.860 & $1.19 \times 10^{-2}$ & -3.860 & $<1.00 \times 10^{-2}$ \\
\hline
\end{tabular}

\subsection{Stock Reproduction Model}

Table 7 shows the results for stock reproduction models using variables which showed most significant relationships within each group of variables with pond smelt catch in Lake Kasumigaura and Kitaura in Table 4. For Lake Kasumigaura we used $l_{t}$ and $w_{t-1}$ and for Lake Kitaura we used $l_{t}$ and $z_{t-1}$ as independent variables for pond smelt in each lake. From Table 7, models (i) had the highest $R^{2}$ and lowest AIC value for pond smelt in Lake Kasumigaura and model (iv) for Lake Kitaura. Both models incorporated TP as an independent variable which made sense ecologically since the variable belonged intrinsically to the two lakes. Both models also included LOTI for the latitude band which incorporates Lake Kasumigaura and Kitaura within the band. LOTI can be said to have indirect correlation to pond smelt since it is a climatic variable which can be said to be a climatic indicator of pond smelt trajectory to some degree.

Figure 4 shows the trajectory of the referred pond smelt catch in Lake Kasumigaura and the trajectory resulting from model (i, Table 7). The predicted catch seems to fit quite well with the referred catch for Lake Kasumigaura. In Figure 5 the predicted and referred catch from model (iv, Table 7) for pond smelt in Lake Kitaura are shown. The fitness of the predicted catch with referred catch is quite good.

Figure 6 shows the linear correlation of the predicted and referred catch of pond smelt for Lake Kasumigaura from model (i, Table 7) and Lake Kitaura from model (iv, Table 7). The determination coefficients were 0.654 and 0.721 respectively. The correlations for both the lakes were quite significant statistically.

Table 8 shows the results of stock reproduction models for the pond smelt CPUE in Lake Kasumigaura and Kitaura from 1998 to 2008 using independent variables of TP and LOTI from Table 2. Model (i) and (iii) are most significant for Lake Kasumigaura and Kitaura respectively and their plots against the referred CPUE for 
Table 7. Models using multiple variables selected from Table 4 for Lake Kasumigaura and Kitaura. Some parameters are shown for different models for the Japanese pond smelt (H. nipponensis) showing the highest $R^{2}$ and lowest AIC values. Values are only shown for models exhibiting significant parameter estimates and model significance at $p<0.05$.

\begin{tabular}{|c|c|c|c|c|c|}
\hline \multicolumn{6}{|c|}{ Lake Kasumigaura } \\
\hline & Model & $R$ & $R^{2}$ & $p$-value & $\begin{array}{c}\text { AIC } \\
\text { value }\end{array}$ \\
\hline i) & $\ln \left(C_{u, t}\right)=7.08+4.93 \times 10^{-4} \times l_{t}^{2}-4.14 \times 10^{-6} \times l_{t}^{3}-19.24 \times w_{t-1}$ & 0.654 & 0.427 & $1.55 \times 10^{-5}$ & 495 \\
\hline ii) & $\ln \left(C_{u, t}\right)=6.13+5.34 \times 10^{-4} \times l_{t}^{2}-4.50 \times 10^{-6} \times l_{t}^{3}-866.90 \times w_{t-1}^{3}$ & 0.639 & 0.408 & $2.76 \times 10^{-5}$ & 497 \\
\hline iii) & $\ln \left(C_{u, t}\right)=5.75+0.193 \times\left(l_{t} \times w_{t-1}\right)$ & 0.560 & 0.315 & $3.74 \times 10^{-4}$ & 502 \\
\hline \multicolumn{6}{|c|}{ Lake Kitaura } \\
\hline iv) & $\ln \left(C_{v, t}\right)=8.56-0.039 \times l_{t}-4.24 \times 10^{-6} \times l_{t}^{3}-108.0 \times z_{t-1}+88.5 \times z_{t-1}^{2}+1.01 \times\left(l_{t} \times z_{t-1}\right)$ & 0.721 & 0.521 & $6.87 \times 10^{-7}$ & 437 \\
\hline v) & $\ln \left(C_{v, t}\right)=6.30+5.67 \times 10^{-4} \times l_{t}^{2}-5.39 \times 10^{-6} \times l_{t}^{3}-15.29 \times z_{t-1}$ & 0.696 & 0.484 & $2.48 \times 10^{-6}$ & 440 \\
\hline vi) & $\ln \left(C_{v, t}\right)=5.56+6.09 \times 10^{-4} \times l_{t}^{2}-5.66 \times 10^{-6} \times l_{t}^{3}-63.01 \times z_{t-1}^{3}$ & 0.684 & 0.467 & $4.34 \times 10^{-6}$ & 441 \\
\hline
\end{tabular}

Table 8. Models using multiple variables selected from Table 2 for Lake Kasumigaura and Kitaura. Some parameters are shown for different models for the Japanese pond smelt (H. nipponensis) CPUE from 1998 to 2008 with highest $R^{2}$ and lowest AIC values. Values are only shown for models exhibiting significant parameter estimates and model significance at $p<$ 0.05 .

\begin{tabular}{|c|c|c|c|c|c|}
\hline \multicolumn{6}{|c|}{ Lake Kasumigaura } \\
\hline \multicolumn{2}{|r|}{ Model } & $R$ & $R^{2}$ & $p$-value & $\begin{array}{l}\text { AIC } \\
\text { value }\end{array}$ \\
\hline i) & $\ln \left(P_{x, t}\right)=14.04+1.96 \times 10^{-3} \times l_{t}^{2}-298.20 \times w_{t}+3.82 \times\left(l_{t} \times w_{t}\right)$ & 0.919 & 0.844 & $6.40 \times 10^{-5}$ & 69 \\
\hline \multicolumn{2}{|r|}{ ii) $\ln \left(P_{x, t}\right)=1.31+0.424 \times\left(l_{t} \times w_{t}\right)$} & 0.909 & 0.827 & $1.04 \times 10^{-4}$ & 70 \\
\hline \multicolumn{6}{|c|}{ Lake Kitaura } \\
\hline iii) & $\ln \left(P_{y, t}\right)=2.28-4.55 \times 10^{-2} \times l_{t}-30.35 \times z_{t}$ & 0.887 & 0.786 & $2.75 \times 10^{-4}$ & 74 \\
\hline & $\ln \left(P_{y, t}\right)=2.63+3.06 \times 10^{2} \times l^{2}+0.417 \times\left(l_{t} \times z_{t}\right)$ & 0.880 & 0.774 & $3.54 \times 10^{-4}$ & 75 \\
\hline
\end{tabular}

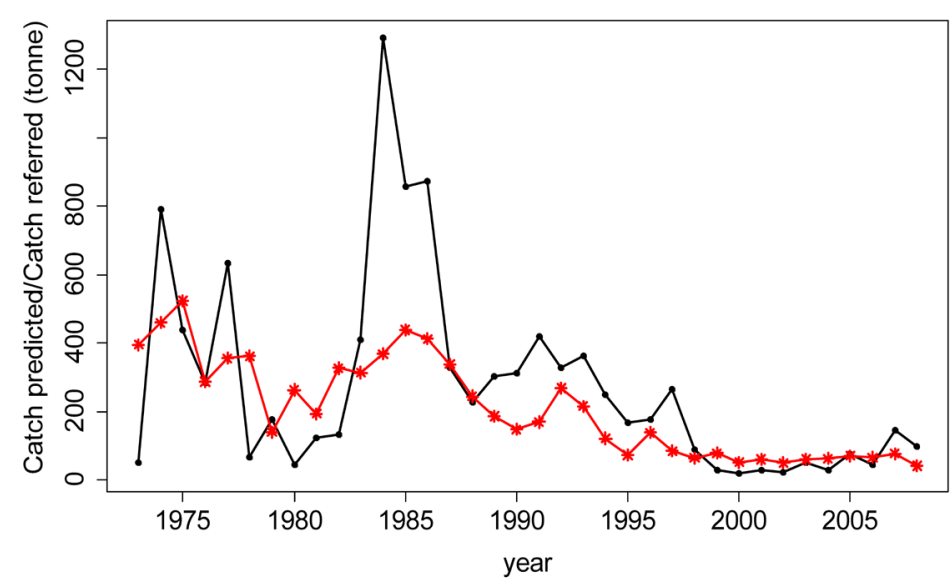

Figure 4. Graph showing the actual catch dynamics of the Japanese pond smelt (H. nipponensis) in Lake Kasumigaura in black and the dynamics resulting from model (i, Table 7) in red for the years ranging from 1973 to 2008.

pond smelt in each lake shows significantly high fitness (Figure 7 and Figure 8). Despite the differences in time lags for TP data, the structure of the models for the CPUE in Table 8 and for the assumed case for catch in Table 7 


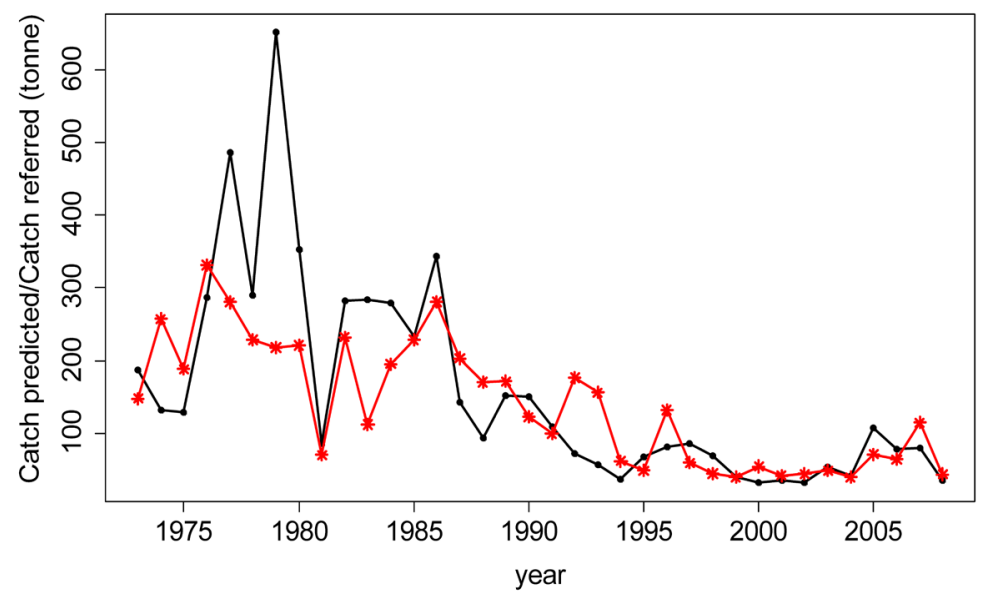

Figure 5. Graph showing the actual catch dynamics of the Japanese pond smelt (H. nipponensis) in Lake Kitaura in black and the dynamics resulting from model (iv, Table 7) in red for the years ranging from 1973 to 2008.

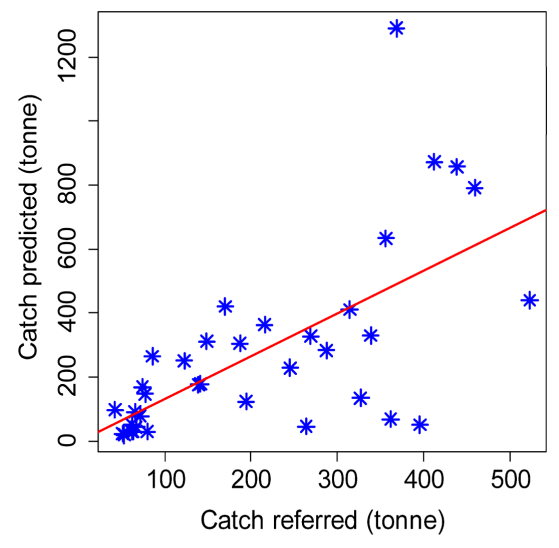

(a)

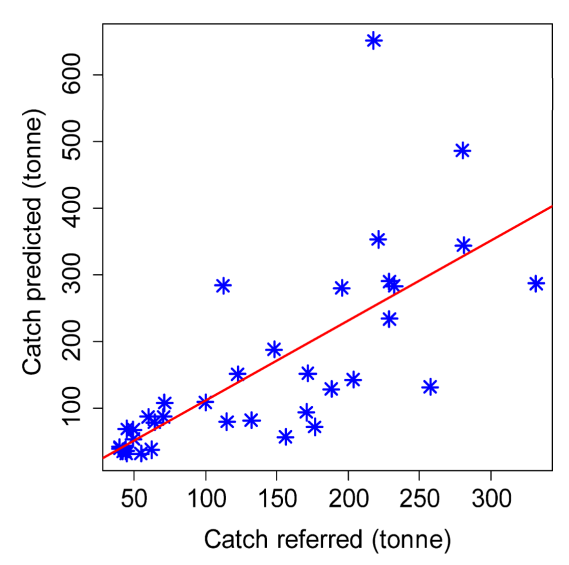

(b)

Figure 6. Graph showing the relationship between the catch predicted and catch referred the Japanese pond smelt ( $H$. nipponensis) for Lake Kasumigaura (a) from model (i, Table 7) and Lake Kitaura (b) from model (iv, Table 7).

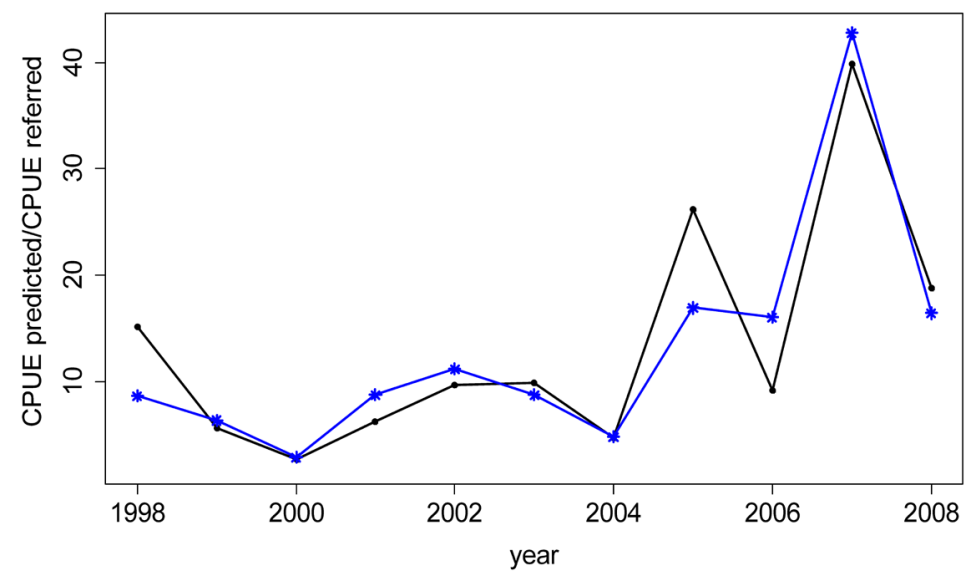

Figure 7. Graph showing the referred CPUE dynamics of the Japanese pond smelt (H. nipponensis) in Lake Kasumigaura in black and the dynamics resulting from model (i, Table 8) in blue for the years ranging from 1998 to 2008. 


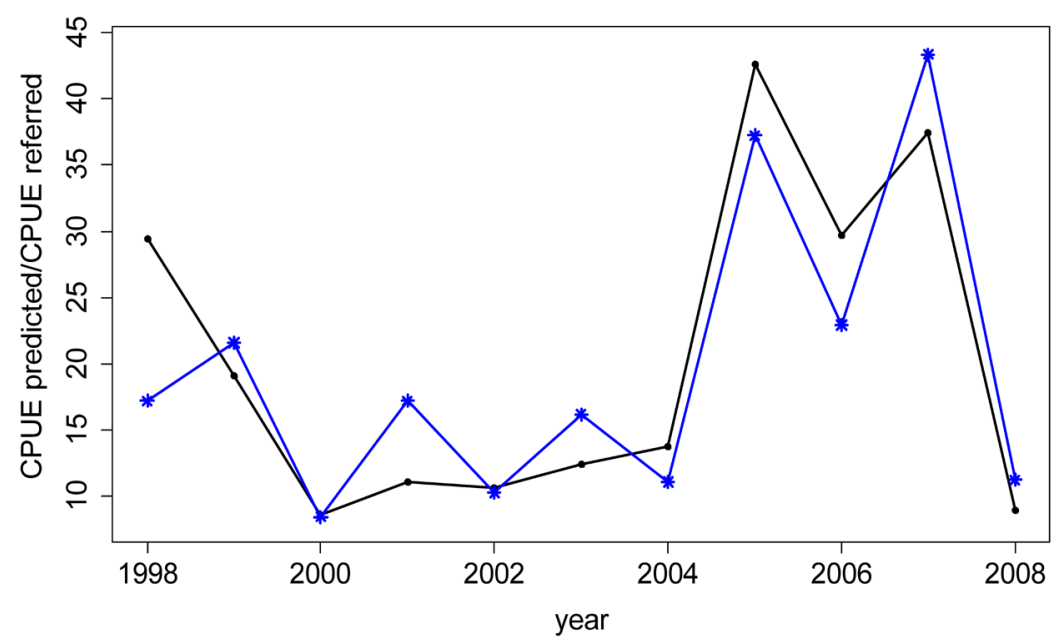

Figure 8. Graph showing the referred CPUE dynamics of the Japanese pond smelt (H. nipponensis) in Lake Kitaura in black and the dynamics resulting from model (iii, Table 8) in blue for the years ranging from 1998 to 2008.

are very similar with both models incorporating the same independent variables which provides further credibility to the assumption of catch as being a suitable presentative of the stock dynamics of pond smelt in Lake Kasumigaura and Kitaura.

\section{Discussion}

For effective management planning of any fishery, it is critical to first understand the underlying factors behind the fluctuation pattern of the organism over a time series. Once the pattern is understood, a much more informed management plan can be strategized. This study was carried out with the intention of determining the factors affecting the fluctuation pattern of the Japanese pond smelt (H. nipponensis) in Lake Kasumigaura and Kitaura for a time series of 37 years. The pond smelt population fluctuates quite vigorously over the years between the extremes of highs and lows as can be seen from Figures 2(a)-(b). While periods with high abundance of stock are probably most beneficial to the fishermen and the fisheries industry of Ibaraki, it is the sustained periods of low catch that can have detrimental impact on the socioeconomic livelihood of the fishermen and the local fisheries industry. For this reason, it is imperative to gain a better understanding of the reasons behind the population fluctuation pattern of the Japanese pond smelt in Lake Kasumigaura and Kitaura.

From the results of this study it was observed that TP levels had the strongest correlation with pond smelt in both Kasumigaura and Kitaura with a lag of one year (Table 4). Since pond smelt has an average life span of one year [28], TP might have direct impact on the pond smelt spawning stock biomass in the previous year or it causes changes in the lake ecosystem which affects pond smelt population in the following year. LOTI $(I)$ has higher correlation with pond smelt in Lake Kasumigaura and Lake Kitaura in the same year compared to a lag of one year (Table 4).

The most suitable models which can significantly reproduce pond smelt trajectory for Lake Kasumigaura and Kitaura from 1973 to 2008 incorporate the variables TP for individual lakes and LOTI for the latitude band $24^{\circ} \mathrm{N}$ to $90^{\circ} \mathrm{N}$ respectively (Table 7). The same variables are incorporated into the models for pond smelt CPUE from 1998 to 2008 for Lake Kasumigaura and Kitaura (Table 8) which provides further support for the models shown in Table 7. In the case of LOTI, the two lakes fall within the latitude band incorporated into the final models. Sharma [12] showed that changes in air temperature have negative impact on cisco (C. artedii) population for over 13,000 lakes in Wisconsin, USA. Since, LOTI which is an index of the global mean land (air) and ocean surface air temperature, does not intrinsically belong to either lakes, it is evident that the impact it has on pond smelt stock fluctuation is indirect in nature. Pond smelt spawning occurs between mid-January to mid-March and harvesting begins in July when they are 4 to 6 months old [28] [31]. LOTI might have indirect effect on the ecological processes affecting the early life stages of pond smelt in the two lakes.

From Table 7 and Table 8 it is clear that both TP level and LOTI affect pond smelt stock and the overall ef- 
fect of the two variables resulted in a good fitness of the predicted catch/CPUE to the referred catch/CPUE of pond smelt in Lake Kasumigaura and Kitaura (Figure 4, Figure 5, Figure 7 and Figure 8). For Lake Kitaura, grasscarp (C. idellus) exhibits a strong relationship with pond smelt (Tables 2-4) and using it as an independent variable could have resulted in models with higher correlations. Aquatic ecosystems are complex and are affected by numerous intrinsic and extrinsic factors interacting [22] to result in the dynamic behavior of biological populations. The fact that grasscarp shows correlation to pond smelt might be due to both fish species being influenced by the same variables. As this was true in the case of grasscarp (Table 5), it could not be used as an independent variable for modeling pond smelt in Lake Kitaura. It is interesting to note that while grasscarp is present in both Lake Kasumigaura and Kitaura, its correlation to pond smelt although false was only detected for one lake (Tables 2-4). Also, even though the models in Table 7 and Table 8 incoporate the same independent variables, their determination coefficients are different. Based on this it can be inferred that although the two lakes are located close to each other geographically, they have some differences in their individual ecosystem dynamics and food web structures.

In this study, pond smelt in both Lake Kasumigaura and Lake Kitaura are impacted by changes in phosphorus content according to the models in Table 7 and Table 8. The relationship of phosphorus content to fish biomass in lakes has also been reported in [41] [18]. Alterations in phosphorus level in lakes is strongly linked to increase in population and human land use activities such as agriculture and development around the lake environment [21] [42]-[45]. Havens [46] reported a strong link between phosphorus loading in Kasumigaura and human developmental activities around the lake.

One recommendation for rehabilitating the pond smelt population in Lake Kasumigaura and Kitaura would be the implementation of abatement programmes for phosphorus loading to the two lakes. This may lead to the recovery of the pond smelt population, however such a step should be taken with great caution. While reduction in phosphorus loading of Lake Kasumigaura and Kitaura may cause the pond smelt population to recover, it can also have adverse effects on other commercially and ecologically important species. Ludsin [19] studied the effect of reduced phosphorus loading on fish community dynamics in Lake Erie, USA from 1969 to 1996 . While some species of fish recovered in abundance through time, other species decreased in abundance. Anthropogenic activities have caused significant negative alterations of freshwater fish communities over the last century [47] [48] and in order to reverse these effects, a deeper understanding of the mechanisms underlying the functioning of freshwater ecosystems is critical.

The structure of the stock reproduction model of pond smelt (H. nipponensis) is very similar for Lake Kasumigaura and Kitaura (Table 7). The catch dynamics of the Japanese pond smelt (H. nipponensis) in Lake Kasumigaura and Kitaura can be effectively determined in proportion to the biotic and abiotic factors, LOTI $\left(l_{t}\right)$ and total phosphorus $\left(w_{t-1}\right)$ for Lake Kasumigaura and LOTI $\left(l_{t}\right)$ and total phosphorus $\left(z_{t-1}\right)$ for Lake Kitaura respectively. The dynamics of the pond smelt for both lakes can be written as

$$
F_{t, g}=a \cdot f\left(e_{1, t-n}, e_{2, t-n}, \cdots, e_{k, t-n}\right)
$$

where $F_{t, g}$ is the catch or CPUE in year $t$ lake $g$, and $f()$ is the function determined by the biotic and abiotic factors $e_{i}(i=1,2, \cdots, k)$ with $n=0,1$. The structure shown by Equation (5) is the same for the Japanese pond smelt in both Lake Kasumigaura and Kitaura.

This study provides evidence that nutrient content and climatic factors can have significant effect on the time series trajectory of fisheries populations in lake environments. This helps to recognize and appreciate the importance of such factors in fishery management. For Lake Kasumigaura and Kitaura investigation efforts need to be directed towards understanding the underlying pathways by which TP and LOTI affect pond smelt populations which will increase understanding of this important lake species for the Ibaraki Prefecture of Japan and provide better management options. From the results of this study it can be said that LOTI is an important climatic factor which has indirect influence on pond smelt stock dynamics in Lakes Kasumigaura and Kitaura and phosphorus loading in the two lakes has adverse impact on pond smelt stock.

\section{Acknowledgements}

We wish to extend our gratitude to the many fishers, research scientists and staff of Ibaraki Prefectural Fisheries Experiment Station, Ibaraki, Japan who aided in the gathering of data on Lake Kasumigaura and Kitaura. 


\section{References}

[1] Saruwatari, T., Lỏpez, J.A. and Pietsch, T.W. (1997) A Revision of Osmerid Genus Hypomesus Gill (Teleostei: Salmoniforms), with the Description of a New Species from the Southern Kurill Islands. Species Diversity, 2, 59-82. http://ci.nii.ac.jp/naid/110002336628/

[2] Hamada, K. (1961) Taxonomic and Ecological Studies of the Genus Hypomesus of Japan. Memoirs of the Faculty of Fisheries, Hokkaido University, 9, 1-55. http://hdl.handle.net/2115/21833

[3] Katayama, S., Kijima, A., Omori, M. and Okata, A. (2001) Genetic Differentiation Among and Within Local Regions in the Pond Smelt, Hypomesus nipponensis. Tohoku Journal of Agricultural Research, 51, 61-75. http://hdl.handle.net/10097/30024

[4] Shiraisi, Y. (1960) The Fisheries Biology and Population Dynamics of Pond Smelt, Hypomesus olidus (Pallas). Bulletin of the Freshwater Fisheries Research Laboratory, 10, 1-263 (in Japanese with English abstract).

[5] Ibaraki Prefecture (2012) Fisheries of Lakes Kasumigaura and Kitaura. In: Fisheries of Ibaraki Prefecture, Ibaraki Prefecture, Mito (in Japanese).

[6] Ibaraki Prefecture (1996) Establishment of the Fish that Represents Ibaraki Prefecture. In: Fisheries of Ibaraki Prefecture, Ibaraki Prefecture, Mito, 40-41 (in Japanese).

[7] Katayama, S. and Kawasaki, T. (1994) Age Determination of Pond Smelt Using Otolith Phase. Tohoku Journal of Agricultural Research, 44, 91-106. http://ir.library.tohoku.ac.jp/re/bitstream/10097/29953/1/KJ00000715054.pdf

[8] McDowall, R.M. (1988) Diadromy in Fishes: Migrations between Freshwater and Marine Environments. Croom Helm, London, 308.

[9] Matsushita, B., Xu, M. and Fukushima. T. (2006) Characterizing the Changes in Landscape Structure in the Lake Kasumigaura Basin, Japan Using a High-Quality GIS Dataset. Landscape and Urban Planning, 78, 241-250.

http://dx.doi.org/10.1016/j.landurbplan.2005.08.003

[10] Sakamoto, D., Takashi, N., Sunoh, N., Iwasaki, J., Niwa, S., Arayama, K., Suzuki, N., Pai-Son., Takagi, K. and Sakuramoto, K. (2014) Population Size Estimation of the Pond Smelt Hypomesus nipponensis in Lake Kasumigaura and Lake Kitaura, Japan. Fisheries Science, 80, 907-914. http://dx.doi.org/10.1007/s12562-014-0791-1

[11] Hanazato, T., Yasuno, M. and Hosomi, M. (1989) Significance of a Low Oxygen Layer for a Daphnia Population in Lake Yunoko, Japan. Hydrobiologia, 185, 19-27. http://dx.doi.org/10.1007/BF00006064

[12] Sharma, S., Vander Zanden, M.J., Magnuson, J.J. and Lyons, J. (2011) Comparing Climate Change and Species Invasion as Drivers of Coldwater Fish Population Extirpations. PloS ONE, 6, e22906. http://dx.doi.org/10.1371/journal.pone.0022906

[13] Toda, H. and Wada, E. (1990) Use of ${ }^{15} \mathrm{~N} /{ }^{14} \mathrm{~N}$ Ratios to Evaluate the Food Source of the Mysid, Neomysis intermedia Czerniawsky, in an Eutrophic Lake in Japan. Hydrobiologia, 194, 85-90. http://dx.doi.org/10.1007/BF00012114

[14] Hasenbein, M., Komoroske, L.M., Connon, R.E., Geist, J. and Fangue, N.A. (2013) Turbidity and Salinity Affect Feeding Performance and Physiological Stress in the Endangered Delta Smelt. Integrative and Comparative Biology, 53, 620-634. http://dx.doi.org/10.1093/icb/ict082

[15] Heithaus, M.R., Wirsing, A.J., Burkholder, D., Thomson, J. and Dill, L.M. (2009) Towards a Predictive Framework for Predator Risk Effects: The Interaction of Landscape Features and Prey Escape Tactics. Journal of Animal Ecology, 78, 556-562. http://dx.doi.org/10.1111/j.1365-2656.2008.01512.x

[16] Atkinson, A., Siegel, V., Pakhomov, E.A., Rothery, P., Loeb, V., Ross, R.M., Quentin, L.B., Schmidt, K., Fretwell, P., Murphy, E.J., Tarling, G.A. and Fleming, A.S. (2008) Oceanic Circumpolar Habitats of Antarctic Krill. Marine Ecology Progress Series, 362, 1-23. http://dx.doi.org/10.3354/meps07498

[17] Bryan, T. and Ludsin, S.A. (2013) Nutrient Inputs Versus Biomass as the Primary Driver of Reservoir Food Webs. Canadian Journal of Fisheries and Aquatic Sciences, 70, 367-380. http://dx.doi.org/10.1139/cjfas-2012-0369

[18] Jeppesen, E., Meerhoff, M., Holmgren, K., González-Bergonzoni, I., Mello, T.F., Declerck, S.A.J., Meester, L.D., Søndergaard, M., Lauridsen, T.L., Bjerring, R., Conde-Porcuna, J.M., Mazzeo, N., Iglesias, C., Reizentein, M. and Malmquist, H.J. (2010) Impacts of Climate Warming on Lake Fish Community Structure and Potential Effects on Ecosystem Function. Hydrobiologia, 646, 73-90. http://dx.doi.org/10.1007/s10750-010-0171-5

[19] Ludsin, S.A., Kershner, M.W., Blocksom, K.A., Knight, R.L. and Stein, R.A. (2001) Life after Death in Lake Erie: Nutrient Controls Drive Fish Species Richness, Rehabilitation. Ecological Applications, 11, 731-746. http://dx.doi.org/10.1890/1051-0761(2001)011[0731:LADILE]2.0.CO;2

[20] Schindler, D.W., Hecky, R.E., Findlay, D.L., Stainton, M.P., Parker, B.R., Paterson, M.J., Beaty, K.G., Lyng, M. and Kasian, S.E.M. (2008) Eutrophication of Lakes Cannot Be Controlled by Reducing Nitrogen Input: Results of a 37-Year Whole-Ecosystem Experiment. PNAS, 105, 11254-11258. http://dx.doi.org/10.1073/pnas.0805108105

[21] Xu, H., Paerl, H.W., Qin, B., Zhu, G. and Gao, G. (2010) Nitrogen and Phosphorus Inputs Control Phytoplankton 
Growth in Eutrophic Lake Taihu, China. Limnology and Oceanography, 55, 420-432. http://dx.doi.org/10.4319/lo.2010.55.1.0420

[22] Grol, M.G.G., Nagelkerken, I., Rypel, A.L. and Layman, C.A. (2011) Simple Ecological Trade-Offs Give Rise to Emergent Cross-Ecosystem Distributions of a Coral Reef Fish. Oecologia, 165, 79-88. http://dx.doi.org/10.1007/s00442-010-1833-8

[23] Hayes, D.B., Ferreri, C.P. and Taylor, W.M. (1996) Linking Fish Habitat to Their Population Dynamics. Canadian Journal of Fisheries and Aquatic Sciences, 53, 383-390. http://dx.doi.org/10.1139/f95-273

[24] Feyrer, F., Nobriga, M.L. and Sommer, T.R. (2007) Multidecadal Trends for Three Declining Fish Species: Habitat Patterns and Mechanisms in the San Fransisco Estuary, California, USA. Canadian Journal of Fisheries and Aquatic Sciences, 64, 723-734. http://dx.doi.org/10.1139/f07-048

[25] Rose, K.A. (2000) Why Are Quantitative Relationships between Environmental Quality and Fish Populations So Elusive? Ecological Applications, 10, 367-385. http://dx.doi.org/10.1890/1051-0761(2000)010[0367:WAQRBE]2.0.CO;2

[26] Nemoto, T. (1995) Stock Abundance of Pond Smelt in Lake Kasumigaura from 1990 to 1992. Bulletin of the Ibaraki Prefectural Freshwater Fisheries Experimental Station, 31, 92-97. (In Japanese)

[27] Kubota, J. (2002) Population Trend on the Pond Smelt and Ice Fish in Lakes Kasumigaura and Kitaura. Bulletin of the Ibaraki Prefectural Freshwater Fisheries Experimental Station, 37, 1-28. (In Japanese)

[28] Kasebayashi, T. and Nakano, I. (1961) Fishery Biological Studies of Pond Smelt, Hypomesus olidus in Lake Kasumigaura VI. Report of Ibaraki Prefectural Fisheries Station of Lakes Kasumigaura Kitaura, 6, 1-64.

[29] Nemoto, T. (1993) Fisheries Management and Population Trend on the Pond Smelt in Lake Kasumigaura. Bulletin of the Ibaraki Prefectural Freshwater Fisheries Experimental Station, 29, 1-12. (In Japanese with English Abstract)

[30] Nemoto, T. (2012) Numerical Estimation of the Amount of Pond Smelt Hypomesus nipponensis in Lake Kasumigaura at the End of Fishery Season in the Two Typical Yield as a Poor Catch Year in 2002 and Rich Catch Year in 2010. Bulletin of the Ibaraki Prefectural Fisheries Research Institute Freshwater Fisheries Branch Office, 45, 15-23. (In Japanese) http://www.pref.ibaraki.jp/bukyoku/nourin/naisuisi/bulletin/bull45/bull4504.pdf

[31] Arayama, K. (2011) Wakasagi. In: Ibaraki Gyogancho Hensan Committee, Ed., Ibaraki Gyogancho (In Japanese), Ibaraki Prefectural Government, Ibaraki, 79-81. http://www.pref.ibaraki.jp/bukyoku/nourin/naisuisi/gyoganchou/_userdata/079_Wakasagi.pdf

[32] Dickey, D.A. and Fuller, W.A. (1979) Distribution of the Estimators for Autoregressive Time Series with a Unit Root. Journal of the American Statistical Association, 74, 427-431. http://dx.doi.org/10.2307/2286348

[33] Kwiatkowski, D., Phillips, P.C.B., Schmidt, P. and Shin, Y. (1992) Testing the Null Hypothesis of Stationarity against the Alternative of a Unit Root. Journal of Econometrics, 54, 159-178. http://dx.doi.org/10.1016/0304-4076(92)90104-Y

[34] MacKinnon, J.G. (1996) Numerical Distribution Functions for Unit Root and Cointegration Tests. Journal of Applied Econometrics, 11, 601-618. http://dx.doi.org/10.1002/(SICI)1099-1255(199611)11:6<601::AID-JAE417>3.0.CO;2-T

[35] Myers, R.H., Montgomery, D.C. and Anderson-Cook, C.M. (2009) Response Surface Methodology: Process and Product Optimization Using Designed Experiments. John Wiley and Sons, Hoboken.

[36] Buchanan, R.L. and Phillips, J.G. (1990) Response Surface Model for Predicting the Effects of Temperature, pH, Sodium Chloride Content, Sodium Nitrate Concentration and Atmosphere on the Growth of Listeria monocytogenes. Journal of Food Protection, 53, 370-381.

[37] Bezerra, M.A., Santelli, R.E., Oliveira, E.P., Villar, L.S. and Escaleira, L.A. (2008) Response Surface Methodology (RSM) as a Tool for Optimization in Analytical Chemistry. Talanta, 76, 965-977. http://dx.doi.org/10.1016/j.talanta.2008.05.019

[38] Box, G.E. and Behnken, D.W. (1960) Some New Three Level Designs for the Study of Quantitative Variables. Technometrics, 2, 455-475. http://dx.doi.org/10.2307/1266454

[39] Akaike, H. (1981) Likelihood of a Model and Information Criteria. Journal of Econometrics, 16, 3-14. http://dx.doi.org/10.1016/0304-4076(81)90071-3

[40] R Core Team (2013) R: A Language and Environment for Statistical Computing. Vienna. http://www.r-project.org/

[41] Yurk, J.J. and Ney, J.J. (1989) Phosphorus-Fish Community Biomass Relationships in Southern Appalachian Reservoirs: Can Lakes Be Too Clean for Fish? Lake and Reservoir Management, 5, 83-90. http://dx.doi.org/10.1080/07438148909354402

[42] Evans, D.O., Nicholls, K.H., Allen, Y.C. and McMurtry, M.J. (1996) Historical Land Use, Phosphorus Loading, and 
Loss of Fish Habitat in Lake Simcoe, Canada. Canadian Journal of Fisheries and Aquatic Sciences, 53, 194-218. http://dx.doi.org/10.1139/f96-012

[43] Johnson, M.G. and Nicholls, K.H. (1989) Temporal and Spatial Variability in Sediment and Phosphorus Loads to Lake Simcoe, Ontario. Journal of Great Lakes Research, 15, 265-282. http://dx.doi.org/10.1016/S0380-1330(89)71481-7

[44] Wilson, J.P. and Ryan, C.M. (1988) Landscape Change in the Lake Simcoe-Couchiching Basin, 1800-1983. Canadian Geographer, 32, 206-222. http://dx.doi.org/10.1111/j.1541-0064.1988.tb00874.x

[45] Wilson, J.P. (1989) Soil Erosion from Agricultural Land in the Lake Simcoe-Couchiching Basin, 1800-1981. Canadian Journal of Soil Science, 69, 137-151. http://dx.doi.org/10.4141/cjss89-013

[46] Havens, K.E., Fukushima, T., Xie, P., Iwakuma, T., James, R.T., Takamura, N., Hanazato, T. and Yamamoto, T. (2001) Nutrient Dynamics and the Eutrophication of Shallow Lakes Kasumigaura (Japan), Donghu (PR China), and Okeechobee (USA). Environmental Pollution, 111, 263-272. http://dx.doi.org/10.1016/S0269-7491(00)00074-9

[47] Carpenter, S.R., Caraco, N.F., Correll, D.L., Howarth, R.W., Sharply, A.N. and Smith, V.H. (1998) Nonpoint Pollution of Surface Waters with Phosphorus and Nitrogen. Ecological Applications, 8, 559-568. http://dx.doi.org/10.1890/1051-0761(1998)008[0559:NPOSWW]2.0.CO;2

[48] Naiman, R.J., Magnuson, J.J., McKnight, D.M. and Stanford, J.A. (1995) The Freshwater Imperative: A Research Agenda. Island Press, Washington DC. 